\title{
Comparison of 1 - and 2-year screening intervals for women undergoing screening mammography
}

\author{
ES Wai", , Y D'yachkova ${ }^{2}$, IA Olivotto', S Tyldesley ${ }^{3}$, N Phillips ${ }^{2}$, LJ Warren ${ }^{4}$ and AJ Coldman ${ }^{2}$ \\ 'Radiation Therapy Program, BC Cancer Agency, Vancouver Island Centre, 2410 Lee Ave, Victoria, BC, Canada V8R 6V5; ${ }^{2}$ Population and Preventive \\ Oncology Program, BC Cancer Agency, 8th Floor, 686 West Broadway, Vancouver, BC, Canada V5Z I GI; ${ }^{3}$ Radiation Therapy Program, BC Cancer \\ Agency, Vancouver Centre, 600 West 10th Ave, Vancouver, BC, Canada V5Z 4E6; ${ }^{4}$ Screening Mammography Program of BC, 8th Floor, 686 West \\ Broadway, Vancouver, BC, Canada V5Z IGI
}

We compared the long-term impact of I- and 2-year screening mammography intervals using prognostic, screening, and outcome information for women aged 50-74 years obtained from the Screening Mammography Program of British Columbia in two time periods, prior to 1997 (policy of annual mammography) and after 1997 (biennial mammography). Survival was estimated for both periods using a prognostic model and the expected rate of interval and screen-detected cancers. The likelihood of a screen-detected cancer with annual screening was 2.32 per thousand screens and with biennial screening was 3.32 per thousand screens. The prognostic profile of screen-detected cancers was better than that of interval cancers. Among both screen-detected and interval cancers, the prognostic profiles with annual and biennial screening were similar. The estimated breast cancer-specific survival rates for women undergoing annual and biennial screening mammography were 95.2 and $94.6 \%$ at 5 years, and 90.4 and $89.2 \%$ at 10 years, respectively. Annual compared to biennial mammography was associated with a $1.2 \%$ increase in the estimated 10 -year breast cancer-specific survival for women aged 50-74 years, diagnosed with invasive breast cancer after screening programme attendance. British Journal of Cancer (2005) 92, 96I-966. doi: I 0.1038/sj.bjc.6602393 www.bjcancer.com

Published online 15 February 2005

(c) 2005 Cancer Research UK

Keywords: mammography; screening frequency; screening interval; breast cancer survival

Screening mammography reduces breast cancer mortality (Chu et al, 1988; Chu and Connor, 1991; Nystrom et al, 1993; Kerlikowske et al, 1995; Bjurstam et al, 1997; Alexander et al, 1999; Tabar et al, 2000; Black et al, 2002; Nystrom et al, 2002). A meta-analysis of the randomised screening trials found equivalent mortality reductions (23\%) from approximate annual screening compared to screening every 18-33 months (Kerlikowske et al, 1995). The only randomised trial to address the frequency of recall between screens found that modelled 10- and 15-year breast cancer survival was not significantly different for women undergoing screening mammograms every year $v s$ every 3 years (Breast Screening Frequency Trial Group, 2002).

In British Columbia (BC), the third largest province in Canada with a population of 4.2 million, the population-based Screening Mammography Program (SMPBC) has provided bilateral two-view mammograms to the asymptomatic female residents of $\mathrm{BC}$, aged 40 and older, free of direct payment since 1988 (Olivotto et al, 2000). In 1997, the SMPBC increased its recommended screening interval for women aged 50-74 years from yearly to every 2 years.

We have examined the effect of this change in screening frequency policy. As follow-up time since the policy change is too short to demonstrate a difference in mortality, the impact on breast cancer-specific survival was estimated by applying the

* Correspondence: Dr ES Wai; E-mail: ewai@bccancer.bc.ca Received 16 September 2004; revised 25 November 2004; accepted 15 December 2004; published online 15 February 2005 observed differences in the prognostic profile of cancers diagnosed in women screened at different intervals to a prognostic prediction model.

\section{MATERIALS AND METHODS}

This retrospective study modelled 10-year survival outcomes for women, aged 50-74 years, screened annually and biennially through the SMPBC. Two time periods were compared, prior to 1997 ('annual' screening group) and after 1997 ('biennial' screening group).

\section{Data sources}

Electronic records for participants in the SMPBC were collected from the SMPBC database and the BC Cancer Registry, both of which are administered through the $\mathrm{BC}$ Cancer Agency. The SMPBC database contains demographic, prognostic, and outcome information on all women screened through the programme and maintains active follow-up to ascertain final pathology results for women with abnormal screening mammograms. It is linked every 3 months with the BC Cancer Registry to identify all breast cancers (screen-detected or otherwise) in screened women. The BC Cancer Registry includes notifications of all cancer reported within the province on either pathology reports or death certificates. The capture rate for new cancers was $94 \%$ for the year 1999. Vital status, date, and cause of death are obtained secondary to regular 
electronic linkage with the Vital Statistics Agency, Ministry of Health, Government of British Columbia.

For this study, a cancer was defined as an invasive epithelial cancer of any histology or ductal carcinoma in situ (DCIS) (i.e. sarcoma, lymphomas, phyllodes tumours, and lobular carcinoma in situ lesions were excluded). Cancers were classified as screendetected if an abnormal screen led to a diagnostic sequence that resulted in the detection of a breast cancer. All other cancers were classified as interval cancers. Subjects were assumed to be at risk of developing an interval cancer from the time of one screen until the time of the first of either the subsequent screen, a diagnosis of an interval cancer, death, or the date of December 31, 2001.

\section{'Prognostic' and 'screening' data samples}

Two overlapping sets of data were extracted. The 'prognostic sample' consisted of all cases of unilateral breast cancer diagnosed prior to January 1, 2002 in women ages 50-74 years, who had attended the SMPBC. Prognostic and outcome information for these cases was collected from the SMPBC database.

The 'screening sample' consisted of all women who received at least one screen at ages 50-74 years, between 1988 and December 31,2001 . Each woman's screening history was subdivided into screening intervals, which started immediately after a screen and terminated with the first of: another screen, death, diagnosis of cancer or December 31,2001. Since this was an analysis of recall frequency, women diagnosed with cancer at their first screen were excluded. Only screening intervals in which the woman was aged $50-74$ years at the beginning were used.

\section{'Annual' and 'biennial' screening frequency}

Screening mammograms performed 10-14 months after the prior screen and prior to January 1, 1997 were defined as 'annual' screens. Screening mammograms performed 20-28 months after the prior screen and after December 31, 1997 were defined as 'biennial' screens. These time intervals were created because most women did not return exactly 12 or 24 months after a previous screen. These intervals of 10-14 months, pre-1997, and 20-28 months, post-1997, were chosen to maintain a period clinically similar to the 1- and 2-year screening intervals of primary interest, and to ensure a similar proportion of women returned for rescreening (approximately $50 \%$ for each of the time periods studied). Each screening interval was analysed independently, so that women who had screens prior to and after 1997 could have contributed screening intervals both to the annual and biennial screening groups. As the SMPBC policy change from annual to biennial screening was implemented in July 1997, the information from the entire transition year of 1997 was not used.

\section{Analytic schema/statistical methods}

The following analytic approach was used:

(1) Prognostic model: A Cox proportional hazards model was developed to predict breast cancer-specific survival based on methods published by Tabar et al (1995) and Haybittle et al (1982), using the 'prognostic sample' described above. Age, tumour size ( $\leqslant 9,10-14,15-19,20-29,30-49,50+\mathrm{mm}$, unknown), nodal status (negative, positive, unknown) and histologic grade (well, moderately, or poorly differentiated and unknown) were examined as potential prognostic factors. As it was assumed that the 10-year breast cancer survival from a diagnosis of DCIS was 100\% (Fisher et al, 1999; Julien et al, 2000), DCIS was not included in the model. Tests of significance were based on the partial likelihood method. The underlying hazard was estimated by the Breslow
Table I Distribution of tumour prognostic factors and corresponding adjusted hazard ratio for breast cancer mortality for 5844 invasive breast cancers diagnosed 1988-200 I in women undergoing screening mammograms through SMPBC (prognostic sample)

\begin{tabular}{lccc}
\hline Prognostic factor & $\mathbf{N}(\mathbf{\%})$ & Hazard ratio & $\mathbf{( 9 5 \% ~ C l )}$ \\
\hline $\begin{array}{l}\text { Tumour size (mm) } \\
\text { I-9 }\end{array}$ & $1163(20)$ & 1.0 & \\
$10-14$ & $1478(25)$ & 1.31 & $(1.20,1.43)$ \\
$15-19$ & $1210(21)$ & 1.72 & $(1.45,2.04)$ \\
$20-29$ & $1095(19)$ & 2.25 & $(1.74,2.92)$ \\
$30-49$ & $480(8)$ & 2.95 & $(2.09,4.16)$ \\
$50+$ & $224(4)$ & 3.87 & $(2.51,5.95)$ \\
Unknown & $194(3)$ & 3.36 & $(2.43,4.66)$ \\
& & & \\
Lymph node status & & & \\
Negative & $3608(62)$ & 1.0 & \\
Positive & $1374(23)$ & 3.82 & $(2.91,5.01)$ \\
Unknown & $862(15)$ & 3.36 & $(2.43,4.66)$ \\
& & & \\
Histologic grade & & & \\
Well differentiated & $1583(27)$ & 1.0 & - \\
Moderately differentiated & $2074(36)$ & 1.04 & $(0.71,1.54)$ \\
Poorly differentiated & I295(22) & 3.42 & $(2.42,4.83)$ \\
Unkown & $892(15)$ & 3.36 & $(2.43,4.66)$ \\
\hline
\end{tabular}

$\mathrm{Cl}=$ confidence interval.

estimator. Partial likelihood methods were used to generate approximate confidence interval (Table 1).

(2) Prognostic distribution: The 'screening sample' described above was used to identify cases of cancer falling into the following four groups: (i) interval cases occurring up to 12 months after the previous screen in either the 'annual' or 'biennial' screening group, (ii) screen-detected cases occurring 10-14 months after the previous screen among those in the 'annual' screening group; and for those in the 'biennial' screening group, (iii) interval cases occurring 12-24 months after the previous screen, and (iv) screen-detected cases occurring 20-28 months after the previous screen (Table 2). For each case in a group, the prognostic factors at presentation were used to predict that woman's survival using the prognostic model. These were then averaged across the members of each group to provide an average predicted survival for the particular group at 5 and 10 years (Table 3 ).

(3) Weighting: The distribution of screens (Table 4) and number of cancer cases from the 'screening sample' described above were then used to calculate the rates of cancer expected in each of the above four groups (Table 5) Rates of interval cancers were estimated using the Kaplan-Meier method and rates of screen-detected cancers were calculated using the observed proportions for the groups described earlier. These were then used to create weights reflecting the distribution of cancer cases by screening the frequency group, detection method, and time of detection in the above four groups.

(4) Prediction: The weights (from (3) above) were then applied to the average group survival rates (from (2) above) to provide the predicted 5- and 10-year survival rates.

\section{RESULTS}

Following 897216 screens provided to women aged 50-74 years between 1988 and 2001 at the SMPBC, 5844 cases of invasive, unilateral breast cancer were diagnosed. The distribution of tumour size, grade, and lymph node status at diagnosis is given 
Table 2 Distribution of prognostic factors among interval and screendetected cancers in the screening sample

\begin{tabular}{|c|c|c|c|c|}
\hline \multirow[b]{2}{*}{ Factor } & \multicolumn{4}{|c|}{ Interval cancer (\%)Screen-detected cancer (\%) } \\
\hline & $\begin{array}{c}\leqslant 12 \\
\text { months }\end{array}$ & $\begin{array}{c}12-24 \\
\text { months }\end{array}$ & $\begin{array}{c}10-14 \\
\text { months }\end{array}$ & $\begin{array}{c}20-28 \\
\text { months }\end{array}$ \\
\hline Total number of cases (n) & 656 & 655 & 438 & 692 \\
\hline \multicolumn{5}{|l|}{ Tumour size (mm) } \\
\hline $1-9$ & 11 & 13 & 25 & 28 \\
\hline $10-14$ & 19 & 19 & 33 & 28 \\
\hline $15-19$ & 20 & 20 & 20 & 22 \\
\hline $20-29$ & 26 & 27 & 12 & 14 \\
\hline $30-49$ & 11 & 13 & 6 & 5 \\
\hline $50+$ & 8 & 7 & 2 & I \\
\hline Unknown & 5 & 3 & 2 & 2 \\
\hline \multicolumn{5}{|l|}{ Lymph node status } \\
\hline Negative & 54 & 53 & 67 & 71 \\
\hline Positive & 32 & 32 & 15 & 22 \\
\hline Unknown & 14 & 14 & 18 & 7 \\
\hline \multicolumn{5}{|l|}{ Histologic grade } \\
\hline Well & 21 & 21 & 24 & 34 \\
\hline Mod & 32 & 32 & 47 & 32 \\
\hline Poor & 31 & 31 & 22 & 14 \\
\hline Unknown & 17 & 16 & 7 & 20 \\
\hline \multicolumn{5}{|c|}{ Unknown (size, node, or grade) } \\
\hline None & 25 & 26 & 22 & 26 \\
\hline Any & 75 & 74 & 78 & 74 \\
\hline \multicolumn{5}{|c|}{$\begin{array}{l}\text { ancluding interval cancers diagnosed } 20-28 \text { months after a screen prior to January I, } \\
\text { 1997. 'Prior to January I, 1997. 'After December 31, } 1997 .\end{array}$} \\
\hline \multicolumn{5}{|c|}{$\begin{array}{l}\text { Table } 3 \text { Estimated 5-and } 10 \text {-year breast cancer specific-survival rates by } \\
\text { type of cancer and time from most recent mammogram to diagnosis }\end{array}$} \\
\hline & & & $\begin{array}{c}\text { Estimated } \\
5 \text {-year } \\
\text { survival } \\
\text { rate (\%) }\end{array}$ & $\begin{array}{c}\text { Estimated } \\
\text { I0-year } \\
\text { survival } \\
\text { rate }(\%)\end{array}$ \\
\hline \multirow{2}{*}{\multicolumn{3}{|c|}{$\begin{array}{l}\text { Screen-detected cancer at } 10-14 \text { months } \\
\text { Screen-detected cancer at } 20-28 \text { months }\end{array}$}} & 96.0 & 91.8 \\
\hline & & & 96.1 & 91.9 \\
\hline \multicolumn{3}{|c|}{ Interval cancer $\leqslant 12$ months } & 92.7 & 85.7 \\
\hline \multicolumn{3}{|c|}{ Interval cancer $12-24$ months } & 92.5 & 85.3 \\
\hline
\end{tabular}

in Table 1. The median follow-up from date of diagnosis was 42 months. The overall survival curve for these cases is shown in Figure 1.

In the Cox analysis of the prognostic sample, age was not significantly associated with breast cancer-specific mortality $(P=0.095)$, but size, grade and lymph node status were (Table 1$)$. The category 'unknown' was associated with a similarly poor prognosis for all variables considered and was combined into a composite category of 'unknown for any variable', which was a

Table 4 Distribution of screening intervals for women, age 50-74 years at time of an initial screen, who were re-screened prior to and after 1997

\begin{tabular}{lcr}
\hline Date of screen & Before I997 (\%) & After I997 (\%) \\
\hline Length of interval (months) & & \\
$0-9$ & $1459(0.5)$ & $38(0.0)$ \\
$10-14$ 'annual' & $188709(68)$ & $80767(20)$ \\
$14-19$ & $49585(18)$ & $53908(13)$ \\
$20-28$ 'biennial' & $24940(9)$ & $208723(52)$ \\
$28+$ & $14459(5)$ & $58647(15)$ \\
Total & $279 \mid 52$ & 402083 \\
\hline
\end{tabular}

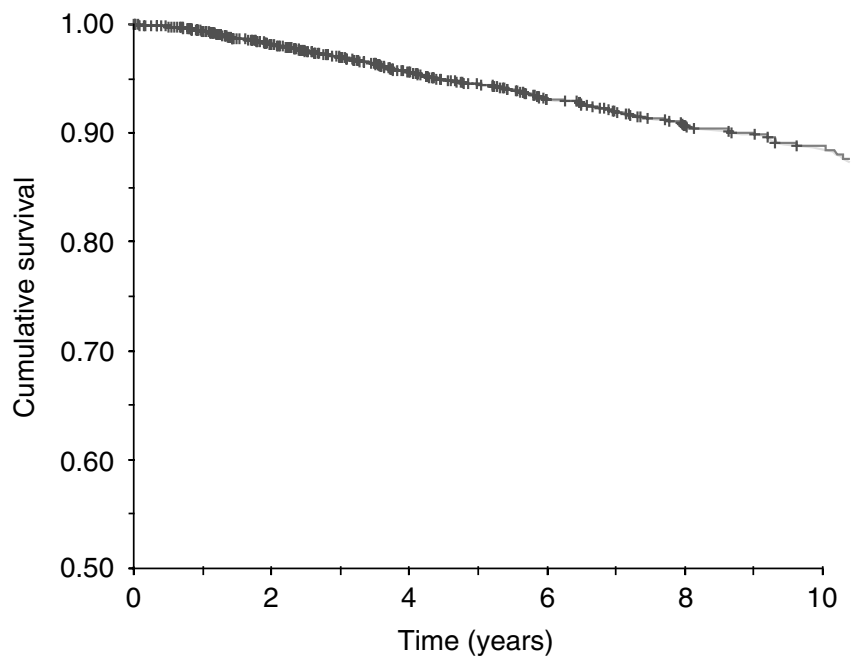

Figure I Breast cancer-specific survival rate for 5844 women ever attending SMPBC and subsequently diagnosed with unilateral invasive breast cancer, 1988-2002.

Table 5 Observed distribution of invasive cancers by screening frequency for women, age 50-74 years, screened over 2 years either annually or biennially

\begin{tabular}{|c|c|c|c|c|}
\hline Mode of detection & $\begin{array}{c}\text { Number } \\
\text { of cases } \\
\text { observed }\end{array}$ & $\begin{array}{l}\text { Number } \\
\text { at risk }^{\mathbf{a}}\end{array}$ & $\begin{array}{c}\text { Observed } \\
\text { rate per } 100000\end{array}$ & $\begin{array}{l}\text { Weighting of } \\
\text { cancers by mode } \\
\text { of detection (\%) }\end{array}$ \\
\hline \multicolumn{5}{|l|}{ Annual screening prior to 1997} \\
\hline Screen detected at $10-14$ months & 438 & 188709 & 232 & 76.6 \\
\hline Interval cancers $\leqslant 12$ months & 305 & 428574 & 71 & 23.4 \\
\hline \multicolumn{5}{|l|}{ Biennial screening after 1997} \\
\hline Interval cancers $12-24$ months & 384 & 250979 & 153 & 27.1 \\
\hline
\end{tabular}

\footnotetext{
${ }^{\mathrm{a}}$ For screen-detected cancers, unit is the number of screens; for interval cancers, unit is person-years.
} 
strongly negative prognostic factor. The hazard ratios for breast cancer mortality for the relevant prognostic factors are provided in Table 1. The observed distribution of prognostic factors for the 2441 cancer cases in the screening sample is shown in Table 2 . The prognostic profile of screen-detected cancers was better than that of interval cancers, while the profile of screen-detected cancers was similar for those found at the 'annual' or the 'biennial' screen. This was also true for interval cancers diagnosed between $0-12$ and 12-24 months. This similarity in prognostic factors translated into minimal differences in estimated 5- and 10-year breast cancerspecific survival rates for each type of tumour, as calculated using the prognostic model developed from the 'prognostic sample' and prognostic factors in the 'screening sample' (Table 3 ).

The distribution of screening intervals is shown in Table 4, the mean interval for those screened prior to 1997 being 12.4 months compared to 24.1 months for those screened after 1997. Approximately two-thirds of the screening intervals prior to 1997 were 10-14 months, whereas only $20 \%$ of those after 1997 were of that length, coincident with the change in SMPBC policy. Approximately half the screening intervals after 1997 were 20-28 months. The age distribution of women aged 50-74 years was similar for the two periods, with means of 61.0 years prior to 1997 and 61.2 years after 1997.

Of those included in the screening sample, the likelihood of having a screen-detected cancer diagnosed with an 'annual' screening interval prior to 1997 was 2.32 per thousand screens (438 out of 188 709) and for women with a 'biennial' screening interval after 1997 was 3.32 (692 out of 208723). The rate of interval cancer by time since last screen was similar over the first 12 months after a screen before 1997 (0.71 per 1000) and after 1997 (0.80 per 1000). The cumulative rate of interval cancers by 24 months was 2.33 per 1000 after 1997. The resulting estimated numbers of screen-detected and interval-invasive cancers per 100000 women screened and per 100000 person-years, respectively, for a period of 2 years, either 'annually' before 1997 or 'biennially' after 1997 are given in Table 5. The overall numbers of invasive and in situ cancers predicted over the 24 months were very similar (716 vs 713) for the two screening frequencies, but more tumours were in situ in the post-1997 period.

Based on the distribution of screen-detected and interval cancers for the two screening strategies, the estimated breast cancer-specific survival rates for women aged 50-74 years undergoing annual as compared to biennial screening mammography were 95.2 and $94.6 \%$, respectively, at 5 years, and 90.4 and $89.2 \%$, respectively, at 10 years (Table 6 ). The absolute difference in estimated breast cancer survival between the annual and biennial screening strategies were $0.6 \%$ at 5 years and $1.2 \%$ at 10 years, corresponding to a relative risk of 0.89 in favour of annual screening, assuming $100 \%$ compliance.

Figure 2 shows the Kaplan-Meier survival curves for all women aged 50-79 attending the SMPBC, diagnosed with invasive, unilateral breast cancer prior to and after 1997. There was no difference in observed survival for patients diagnosed prior to or after the policy change of annual to biennial screening for women diagnosed with breast cancer after SMPBC attendance.

\section{DISCUSSION}

This large, retrospective, population-based study of women aged 50-74 has found that annual screening mammography was associated with a higher proportion of screen-detected cancers than was biennial screening. The distribution of cancers and prognostic profiles translated into small absolute differences in modelled 5- and 10-year breast cancer-specific survival in a hypothetical cohort of 100000 screens performed either annually or biennially ( 0.6 and $1.2 \%$, respectively), in favour of the annually screened group. In keeping with this, there was no difference in
Table 6 Predicted 5- and 10-year survival rates by frequency of screening ${ }^{a}$

\begin{tabular}{lcc}
\hline $\begin{array}{l}\text { Screening } \\
\text { frequency }\end{array}$ & $\begin{array}{c}\text { Predicted 5-year } \\
\text { survival rate (\%) }\end{array}$ & $\begin{array}{c}\text { Predicted 10-year } \\
\text { survival rate (\%) }\end{array}$ \\
\hline 'Annual' & 95.2 & 90.4 \\
'Biennial' & 94.6 & 89.2 \\
\hline
\end{tabular}

Predicted breast cancer-specific survival rates based on expected prognostic profile and distribution of interval and screen-detected cancers.

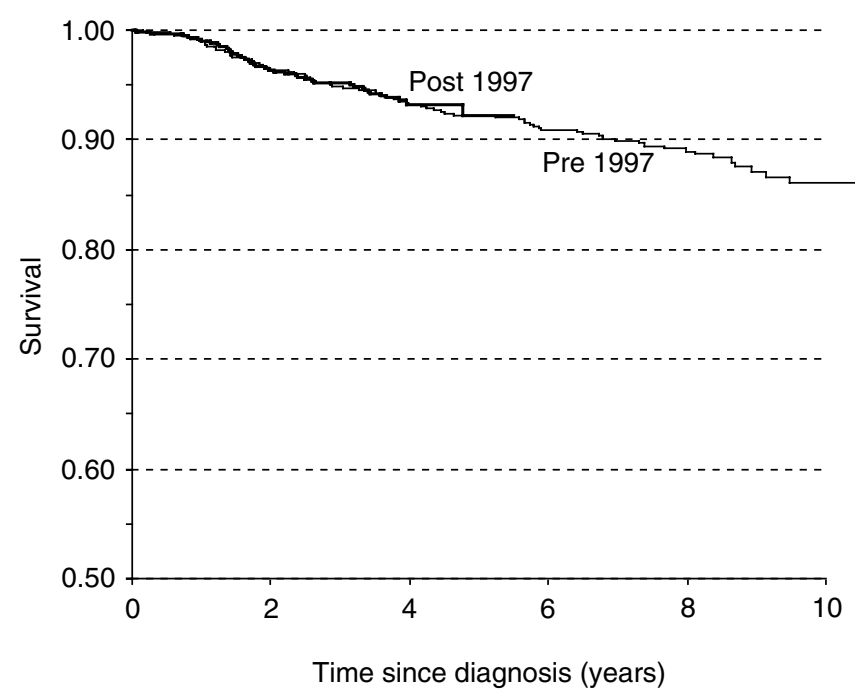

Figure 2 Observed survival curves for women aged 50-79 at screening and diagnosed with breast cancer prior to 1997 (annual screening period) or after 1997 (biennial screening period). Cases prior to 1997 were either interval cases $\leqslant 12$ months or screen-detected at $10-14$ months; those diagnosed after 1997 were either interval cases $\leqslant 24$ months or screendetected at $20-28$ months.

observed survival in women diagnosed with ipsilateral, invasive breast cancer undergoing screening mammography during the time of an annual or biennial screening policy.

The predicted differences in 10-year breast cancer survival were similar to the findings of the only randomised trial addressing this issue, the United Kingdom Co-ordinating Committee on Cancer Research Randomised Trial performed (Breast Screening Frequency Trial Group, 2002). That study randomised women, aged 50-62 years, with a normal prevalent screen in the UK National Health Services (NHS) Breast Screening Programme, to a conventional incident screen after an interval of 3 years (control arm) or to three annual screenings (study arm).

The BSFTG randomised trial found that the incidence of breast cancers was 2.44 per thousand per annum in the study arm and 2.15 in the control arm, similar to the estimates from our study. Also, $71 \%$ of the cancers were screen-detected in the annual recall (study) arm compared to $50 \%$ in the 3-year recall (control) arm, similar to the rates, $76 \%$ in the annual and $58 \%$ in biennial screening cohorts found in this study. As expected, the shorter screening interval was associated with a higher proportion of screen-detected cancers, compared to interval cancers, but this translated to only a small absolute difference in the estimated 10year breast cancer-specific survival: approximately $2 \%$ in the randomised trial and $1 \%$ in the current study.

In a meta-analysis of data from the randomised trials, there was no difference in the reduction in breast cancer mortality among women aged 50-74 with planned screening intervals of less than 
18 months compared to those with longer intervals of 18-33 months (Kerlikowske et al, 1995).

Computer modelling simulations suggest that breast cancer mortality reductions improve with shorter screening intervals, with improvements as much as from $26 \%$, for mammography performed every 5 years, to 66\%, annual mammography (Szeto and Devlin, 1996; Michaelson et al, 1999, 2000; Fett, 2001). In contrast, Jansen et al used modelling to show that shorter screening intervals may be associated with greater detection of 'excess' tumours that would not have been detected before the subject died of other causes, and that the overall benefit to the population with respect to breast cancer mortality was greater when a larger proportion of the population were screened at a lower frequency compared to a smaller proportion screened more frequently (Jansen and Zoetelief, 1997).

Retrospective studies comparing interval and screen-detected cancers have shown that interval cancers are similar to cancers in unscreened women, and that screen-detected cancers generally have better prognostic indicators, with smaller tumours, fewer node-positive tumours, and a larger proportion of in situ tumours (Burrell et al, 1996; Porter et al, 1999). The current study confirms these observations, but of note is the similarity of the prognostic profile of interval cancers for those screened annually and that of interval cancers in those screened biennially, with the same being true for screen-detected cancers.

Retrospective cohort studies that examined prognostic differences of tumours detected in women who self-selected different screening frequencies have generally shown that those screened less frequently have tumours with worse prognostic profiles, including larger tumour size, more lymph node metastases, and fewer cases of isolated in-situ disease (Gabriel et al, 1997; Field et al, 1998; Carlson et al, 1999; Hunt et al, 1999). It has been shown that the higher absolute rate of false-positive screens increased with more frequent screening (Elmore et al, 1998).

A limitation of the current study is that, during the study interval (1995-2002), there could have been improvements in the technical aspects of imaging or in radiologist experience that may have affected detection rates (Kan et al, 2000; Feig, 2002; Haus,
2002; Taplin et al, 2002), although SMPBC data suggest that improved detection is unlikely to explain our observations. Within the SMPBC, women, aged 40-49, were recalled for screening annually both before and after 1997 and comparison of these periods showed little difference, with the cancer detection rate increasing only 0.1 per 1000 for both first and subsequent screens after 1997 (SMPBC unpublished data, December 2003). Another limitation was the incomplete enforcement of the change in screening policy with some women not following the re-screening recommendations in each period. This necessitated a wider range of duration between screens in the era after 1997 to create comparably sized groups for analysis purposes.

In spite of these limitations, this study provides useful information about different screening intervals based on actual data from a large, population-based screening programme that instituted a policy change, in the modern era of two-view, filmscreen mammography. Complete and accurate outcome data were obtained through direct linkage to the provincial cancer registry. The two comparison groups were selected to minimise selection bias. The predicted survival was based on a prognostic model that used cases over the whole period to avoid the survival effect of changes in treatment between the different periods. Thus, the predicted survival was a 'blended' rate of the survival in each period and was applied uniformly to everyone in the study regardless of her date of diagnosis.

In conclusion, this study has shown that annual screening mammography minimally improved the estimated breast cancer survival rates for women aged 50-74 years, as compared to biennial screening at 5 and 10 years, with an absolute projected survival difference of $0.6 \%$ at 5 years and $1.2 \%$ at 10 years for those women diagnosed with breast cancer.

\section{ACKNOWLEDGEMENTS}

This work was supported in part by a grant from the Canadian Breast Cancer Foundation, BC/Yukon chapter.

\section{REFERENCES}

Alexander FE, Anderson TJ, Brown HK, Forrest AP, Hepburn W, Kirkpatrick AE, Muir BB, Prescott RJ, Smith A (1999) 14 years of follow-up from the Edinburgh randomised trial of breast-cancer screening. Lancet 353(9168): 1903-1908

Bjurstam N, Bjorneld L, Duffy SW, Smith TC, Cahlin E, Eriksson O, Hafstrom LO, Lingass H, Mattsson J, Persson S, Rudenstam CM, SaveSoderbergh J (1997) The Gothenburg breast screening trial: first results on mortality, incidence, and mode of detection for women ages 39-49 years at randomization. Cancer 80(11): $2091-2099$

Black WC, Haggstrom DA, Gilbert Welch H (2002) All-cause mortality in randomized trials of cancer screening. J Natl Cancer Inst 94(3): $167-173$

Breast Screening Frequency Trial Group (BSFTG) (2002) The frequency of breast cancer screening: results from the UKCCCR Randomised Trial. United Kingdom Co-ordinating Committee on Cancer Research. Eur J Cancer 38(11): $1458-1464$

Burrell HC, Sibbering DM, Wilson AR, Pinder SE, Evans AJ, Yeoman LJ, Elston CW, Ellis IO, Blamey RW, Robertson JF (1996) Screening interval breast cancers: mammographic features and prognosis factors. Radiology 199(3): $811-817$

Carlson KL, Helvie MA, Roubidoux MA, Kleer CG, Oberman HA, Wilson TE, Pollak EW, Rochester AB (1999) Relationship between mammographic screening intervals and size and histology of ductal carcinoma in situ. AJR Am J Roentgenol 172(2): 313-317

Chu KC, Connor RJ (1991) Analysis of the temporal patterns of benefits in the Health Insurance Plan of Greater New York trial by stage and age. Am J Epidemiol 133(10): 1039-1049
Chu KC, Smart CR, Tarone RE (1988) Analysis of breast cancer mortality and stage distribution by age for the Health Insurance Plan clinical trial. J Natl Cancer Inst 80(14): 11251132

Elmore JG, Barton MB, Moceri VM, Polk S, Arena PJ, Fletcher SW (1998) Ten-year risk of false positive screening mammograms and clinical breast examinations. $N$ Engl J Med 338(16): 1089-1096

Feig SA (2002) Image quality of screening mammography: effect on clinical outcome. AJR Am J Roentgenol 178(4): 805-807

Fett MJ (2001) Computer modelling of the Swedish two county trial of mammographic screening and trade offs between participation and screening interval. J Med Screen 8(1): 39-45

Field LR, Wilson TE, Strawderman M, Gabriel H, Helvie MA (1998) Mammographic screening in women more than 64 years old: a comparison of 1- and 2-year intervals. AJR Am J Roentgenol 170(4): $961-965$

Fisher B, Dignam J, Wolmark N, Wickerham DL, Fisher ER, Mamounas E, Smith R, Begovic M, Dimitrov NV, Margolese RG, Kardinal CG, Kavanah MT, Fehrenbacher L, Oishi RH (1999) Tamoxifen in treatment of intraductal breast cancer: National Surgical Adjuvant Breast and Bowel Project B-24 randomised controlled trial. Lancet 353(9169): $1993-2000$

Gabriel H, Wilson TE, Helvie MA (1997) Breast cancer in women 65-74 years old: earlier detection by mammographic screening. AJR Am J Roentgenol 168(1): 23-27

Haus AG (2002) Historical technical developments in mammography. Technol Cancer Res Treat 1(2): 119-126 
Haybittle JL, Blamey RW, Elston CW, Johnson J, Doyle PJ, Campbell FC, Nicholson RI, Griffiths K (1982) A prognostic index in primary breast cancer. Br J Cancer 45(3): 361 -366

Hunt KA, Rosen EL, Sickles EA (1999) Outcome analysis for women undergoing annual versus biennial screening mammography: a review of 24,211 examinations. AJR Am J Roentgenol 173(2): 285-289

Jansen JT, Zoetelief J (1997) Optimisation of mammographic breast cancer screening using a computer simulation model. Eur J Radiol 24(2): 137 - 144

Julien JP, Bijker N, Fentiman IS, Peterse JL, Delledonne V, Rouanet P, Avril A, Sylvester R, Mignolet F, Bartelink H, Van Dongen JA (2000) Radiotherapy in breast-conserving treatment for ductal carcinoma in situ: first results of the EORTC randomised phase III trial 10853. EORTC Breast Cancer Cooperative Group and EORTC Radiotherapy Group. Lancet 355(9203): 528-533

Kan L, Olivotto IA, Warren Burhenne LJ, Sickles EA, Coldman AJ (2000) Standardized abnormal interpretation and cancer detection ratios to assess reading volume and reader performance in a breast screening program. Radiology 215(2): 563-567

Kerlikowske K, Grady D, Rubin SM, Sandrock C, Ernster VL (1995) Efficacy of screening mammography. A meta-analysis. JAMA 273(2): 149-154

Michaelson JS, Halpern E, Kopans DB (1999) Breast cancer: computer simulation method for estimating optimal intervals for screening. Radiology 212(2): $551-560$

Michaelson JS, Kopans DB, Cady B (2000) The breast carcinoma screening interval is important. Cancer 88(6): $1282-1284$

Nystrom L, Andersson I, Bjurstam N, Frisell J, Nordenskjold B, Rutqvist L (2002) Long-term effects of mammography screening: updated overview of the Swedish randomized trials. Lancet 359: 909-919
Nystrom L, Rutqvist LE, Wall S, Lindgren A, Lindqvist M, Ryden S, Andersson I, Bjurstam N, Fagerberg G, Frisell J et al (1993) Breast cancer screening with mammography: overview of Swedish randomised trials. Lancet 341 (8851): $973-978$

Olivotto IA, Kan L, d'Yachkova Y, Burhenne LJ, Hayes M, Hislop TG, Worth AJ, Basco VE, King S (2000) Ten years of breast screening in the Screening Mammography Program of British Columbia, 1988-97. J Med Screen 7(3): $152-159$

Porter PL, El-Bastawissi AY, Mandelson MT, Lin MG, Khalid N, Watney EA, Cousens L, White D, Taplin S, White E (1999) Breast tumor characteristics as predictors of mammographic detection: comparison of interval- and screen-detected cancers. I Natl Cancer Inst 91(23): $2020-2028$

Szeto KL, Devlin NJ (1996) The cost-effectiveness of mammography screening: evidence from a microsimulation model for New Zealand. Health Policy 38(2): $101-115$

Tabar L, Fagerberg G, Chen HH, Duffy SW, Smart CR, Gad A, Smith RA (1995) Efficacy of breast cancer screening by age. New results from the Swedish Two-County Trial. Cancer 75(10): 2507-2517

Tabar L, Vitak B, Chen HH, Duffy SW, Yen MF, Chiang CF, Krusemo UB, Tot T, Smith RA (2000) The Swedish Two-County Trial twenty years later. Updated mortality results and new insights from long-term followup. Radiol Clin North Am 38(4): 625-651

Taplin SH, Rutter CM, Finder C, Mandelson MT, Houn F, White E (2002) Screening mammography: clinical image quality and the risk of interval breast cancer. AJR Am J Roentgenol 178(4): $797-803$ 